\title{
Influence of low ozone episodes on erythemal UV-B radiation in Austria
}

\author{
Matthias Schwarz ${ }^{1,2,3}$ • Dietmar J. Baumgartner ${ }^{4} \cdot$ Helga Pietsch $^{2} \cdot$ Mario Blumthaler $^{5}$. \\ Philipp Weihs ${ }^{6} \cdot$ Harald E. Rieder ${ }^{1,2,7}$
}

Received: 6 December 2016 / Accepted: 12 May 2017 /Published online: 17 June 2017

(C) The Author(s) 2017. This article is an open access publication

\begin{abstract}
This study investigates the influence of low ozone episodes on UV-B radiation in Austria during the period 1999 to 2015. To this aim observations of total column ozone (TCO) in the Greater Alpine Region (Arosa, Switzerland; Hohenpeissenberg, Germany; Hradec Kralove, Czech Republic; Sonnblick, Austria), and erythemal UV-B radiation, available from 12 sites of the Austrian UV-B monitoring network, are analyzed. As previous definitions for low ozone episodes are not particularly suited to investigate effects on UV radiation, a novel threshold approach - considering anomalies - is developed to provide a joint framework for the analysis of extremes. TCO and UV extremes are negatively correlated, although modulating effects of sunshine duration impact the robustness of the statistical relationship. Therefore, information on relative sunshine duration $\left(\mathrm{SD}_{\text {rel }}\right)$, available at (or nearby) UV-B monitoring sites, is included as explanatory variable in the analysis. The joint analysis of anomalies of both
\end{abstract}

Matthias Schwarz

matthias.schwarz@env.ethz.ch

1 Wegener Center for Climate and Global Change (WEGC), University of Graz, Graz, Austria

2 Institute for Geophysics, Astrophysics and Meteorology/Institute of Physics (IGAM/IP), University of Graz, Graz, Austria

3 Institute for Atmospheric and Climate Science, ETH Zurich, Zurich, Switzerland

4 Kanzelhöhe Observatory for Solar and Environmental Research (KSO), University of Graz, Treffen, Austria

5 Division for Biomedical Physics, Innsbruck Medical University, Innsbruck, Austria

6 Institute for Meteorology, University of Natural Resources and Life Sciences (BOKU), Vienna, Austria

7 Austrian Polar Research Institute, Vienna, Austria
$\mathrm{UV}$ index (UVI) and total ozone ( $\triangle \mathrm{UVI}, \Delta \mathrm{TCO})$ and $\mathrm{SD}_{\text {rel }}$ across sites shows that more than $65 \%$ of observations with strongly negative ozone anomalies $(\Delta \mathrm{TCO}<-1)$ led to positive UVI anomalies. Considering only days with strongly positive UVI anomaly ( $\triangle \mathrm{UVI}>1$ ), we find (across all sites) that about $90 \%$ correspond to negative $\Delta \mathrm{TCO}$. The remaining $10 \%$ of days occurred during fair weather conditions $\left(\mathrm{SD}_{\text {rel }} \geq 80 \%\right)$ explaining the appearance of $\Delta \mathrm{UVI}>1$ despite positive TCO anomalies. Further, we introduce an anomaly amplification factor (AAF), which quantifies the expected change of the $\Delta \mathrm{UVI}$ for a given change in $\triangle \mathrm{TCO}$.

\section{Introduction}

The emission of man-made ozone-depleting substances (ODSs), comprising chlorofluorocarbons, hydrochlorofluorocarbons, and bromine species (e.g., methyl bromide), led to significant stratospheric ozone depletion during the last decades of the twentieth century (WMO 2014). Since the detection of the Antarctic ozone hole in the 1980s (e.g., Farman et al. 1985), the scientific community and general public has been concerned by increased ultraviolet radiation (UV) doses due to declining ozone concentrations and related negative effects on human health (WMO 2014). These concerns have broadened the road for the Montreal Protocol, the international treaty for the protection of the ozone layer. Successful implementation of the Montreal Protocol led to a significant decrease in the emission of ODSs (e.g., Engel et al. 2002; Montzka et al. 1996, 1999), and first studies documenting evidence for the effectiveness of the Montreal Protocol appeared in the recent literature (e.g., Mäder et al. 2010; Solomon et al. 2016; WMO 2014). Although ODS concentrations peaked between 1997 and 2001 and have been declining since, they are to date well above 1980 levels and projected to 
remain so in the next few decades (WMO 2014). Simulations of state-of-the-art chemistry climate models project a steady but slow decline in ODS concentrations over the twenty-first century (e.g., Eyring et al. 2010; SPARC-CCMVal 2010), leading to a recovery of the ozone layer to pre- 1980 conditions in the second half of the twenty-first century (WMO 2014).

Although the UV wavelength range $(200-400 \mathrm{~nm})$ of the solar spectrum comprises only a small fraction of the total energy of solar radiation, it is important for human health and photochemistry due to the high energy of photons in this wavelength range. The UV wavelength range is commonly subdivided in three spectral regions: UV-A $(315-400 \mathrm{~nm})$, UV-B (280-315 nm), and UV-C (200-280 nm) (e.g., Commission Internationale de l'Eclairage 1999; World Health Organization 2002).

It is well understood that total column ozone (TCO), cloudiness, and solar zenith angle are the most important factors influencing UV radiation at the surface (e.g., Calbo et al. 2005; Kerr 2003). The total column ozone amount is particularly important as ozone is the dominant atmospheric absorber of UV-B and UV-C radiation (UNEP 1998). Furthermore, UV doses depend strongly on aerosol loading (e.g., Kazadzis et al. 2007; Reuder and Schwander 1999; Ruckstuhl et al. 2008), surface albedo (e.g., Blumthaler and Ambach 1988), and altitude (e.g., Blumthaler et al. 1997; Schmucki and Philipona 2002). Cloudiness often masks the influence of TCO changes on UV radiation and may, depending on cloud type and amount, cancel, reduce, or enhance UV signals (e.g., Bais et al. 1993; Feister et al. 2015; Glandorf et al. 2005; Rieder et al. 2010c; Seckmeyer et al. 1996).

Several studies investigated the evolution of low ozone episodes at mid-latitudes (Anton et al. 2008; Bojkov and Balis 2001; Brönnimann and Hood 2003; Fitzka et al. 2014; Frossard et al. 2013; Hood et al. 2001; Iwao and Hirooka 2006; James 1998; Koch et al. 2005; Krzyscin 2002; Newman et al. 1988; Petzoldt 1999; Rieder et al. 2010a, b, 2011, 2013). The definitions for low ozone episodes, often referred to as ozone miniholes, vary among studies, and to date, only few studies have analyzed changes in the UV field during low ozone episodes and the general connection between low ozone episodes and UV levels (e.g., Anton et al. 2008; Bartlett and Webb 2000; Fragkos et al. 2016; MartinezLozano et al. 2011; McKenzie et al. 1991; Rieder et al. 2010c). Furthermore, no uniform definition for ozone or UV extremes is available. Threshold approaches vary among studies between fixed levels and relative or absolute deviations (with the latter identified as not-optimal choice due to the nonGaussian behavior of TCO data (e.g., Rieder et al. 2010a)). Furthermore, the difference in the northern mid-latitude seasonal cycles of TCO (maxima in late winter/early spring, minima in fall) and UV-B radiation (summertime maxima) complicate the joint analysis of extremes. This study aims on bridging this gap by introducing a joint, anomaly based, framework for the analysis of TCO and UV extremes. This framework is applied to investigate the influence of low ozone episodes on UV radiation in Austria during the period 1999 to 2015.

\section{Data}

In this study, we use (1) TCO data from four sites in the Greater Alpine Region (GAR; Auer et al. (2007)), (2) ground-based UV measurements from 12 sites of the Austrian UV-B monitoring network (Schmalwieser and Schauberger 2001), and (3) sunshine duration data from semi-automatic weather stations of the Zentralanstalt für Meteorologie und Geodynamik, Austria (ZAMG) located at (or nearby) the UV-B monitoring sites. All datasets are available from 1999 to 2015 (besides UV records for GrossEnzersdorf, Gerlitzen, and Hafelekar, starting in 2004) and described in detail in Sects. 2.1-2.3. Substantial year-to-year variability but no statistically significant (at a 95\% level) monthly, seasonal, or annual trends are present in the datasets. The absence of trends is attributed to (1) the time period considered as negative ozone trends have been strongest in the 1980s and early 1990s (WMO 2014) and (2) the limited record length of 17 years.

\subsection{Total column ozone data}

Daily observations of TCO from four ground-based sites: Arosa (ARO, Switzerland), Hohenpeissenberg ( $\mathrm{HOH}$, Germany), Hradec Kralove (HRA, Czech Republic), and Sonnblick (SON, Austria), are used in this study. TCO data for $\mathrm{HOH}$ and HRA were derived from the World Ozone and Ultraviolet Radiation Data Center (WOUDC), while data for SON and ARO were provided by the Institute of Meteorology of the University of Natural Resources and Life Sciences Austria (BOKU) and the Swiss Federal Office of Meteorology and Climatology (MeteoSwiss), respectively. All groundbased ozone datasets analyzed were obtained with Brewer spectrophotometers using the differential optical absorption spectroscopy principle-i.e., measurements of relative intensities of selected UV wavelengths pairs are used, along with known absorption coefficients of ozone and other parameters such as the solar zenith angle and scattering coefficients - to derive TCO at site basis (e.g., Kerr 2002; Kerr et al. 1985). A geographical overview about the location of ground-based TCO monitoring sites is provided in Fig. 1, and information on site altitudes and data completeness for individual TCO monitoring sites is provided in Table 1. 


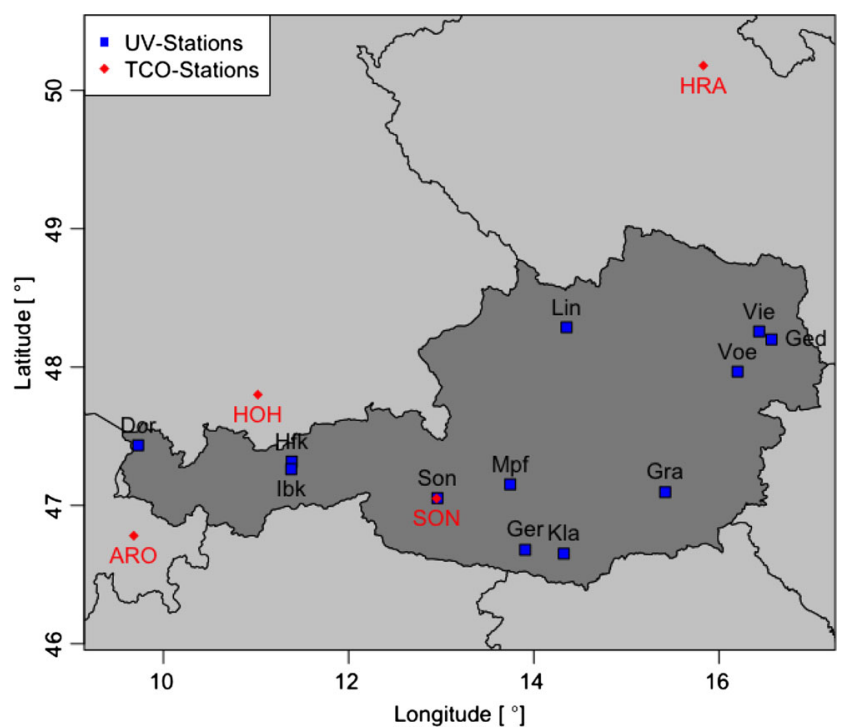

Fig. 1 Geographical overview of UV-B (blue squares) and TCO (red squares) monitoring sites used in this study

\subsection{Ultraviolet radiation data}

The Austrian UV-B monitoring network (Schmalwieser and Schauberger 2001) is operating since 1999 within the scope of the Austrian UV-B monitoring program under the auspices of the Austrian Federal Ministry of Agriculture, Forestry, Environment, and Water Management. UV-B measurements are performed by the Division of Biomedical Physics of the Medical University of Innsbruck (DBP-MUI) in close collaboration with partner institutes/universities. Currently data is available from 12 national monitoring sites and four sites located in proximity to the Austrian border (Munich and Zugspitze (Germany); Davos and Weissfluhjoch (Switzerland)).

Within this study, erythemally weighted UV-B data from 12 monitoring sites in Austria, obtained from the Austrian UV-B monitoring network database hosted by DBP-MUI, were analyzed. The datasets were provided with 30-min temporal resolution in terms of Ultraviolet Radiation Index (UVI) (e.g., World Health Organization 2002). Astronomical calculations have been performed to determine solar zenith angles on site basis, and all UVI measurements between local

Table 1 Overview of site abbreviation, site altitude, and data coverage (1999-2015) for individual total ozone (TCO) monitoring sites located within the Greater Alpine Region

\begin{tabular}{llll}
\hline TCO station & Abbreviation & Altitude (m) & Data coverage (\%) \\
\hline Sonnblick & SON & 3106 & 78.0 \\
Arosa & ARO & 1855 & 87.0 \\
Hohenpeissenberg & HOH & 990 & 80.7 \\
Hradec Kralove & HRA & 300 & 96.0 \\
\hline
\end{tabular}

astronomical sunrise and sunset have been included for calculations of daily mean values of UVI. Information on site altitude, record lengths, and data completeness for individual UV$\mathrm{B}$ monitoring sites is provided in Table 2. Figure 1 provides an overview about the geographical location of the Austrian UV$\mathrm{B}$ monitoring sites.

\subsection{Sunshine duration data}

Continuous information on sunshine duration in Austria is available from the network of semi-automatic weather stations (TAWES), operated by ZAMG. Sunshine duration data from TAWES sites co-located with (or located in close proximity to) UV-B monitoring sites (see Table 2) have been included in the analysis as proxy for cloudiness. As unrobust relationships between daily mean UVI and TCO are found, we include relative sunshine duration $\left(\mathrm{SD}_{\text {rel }}\right.$; fraction of observed to astronomically possible sunshine duration, in \%), as secondary explanatory variable (besides TCO) in our analysis to account for cloud effects.

\section{Methods}

\subsection{A joint threshold approach for the analysis of ozone and UV extremes}

To date, various definitions for low ozone episodes have been presented in the scientific literature. Previous studies used (1) fixed thresholds (e.g., Bojkov and Balis 2001; Brönnimann and Hood 2003), (2) time-varying thresholds based on the deviation from monthly means (e.g., Anton et al. 2008; Koch et al. 2005; Krzyscin 2002), or (3) the application of extreme value theory (e.g., Fitzka et al. 2014; Rieder et al. 2010a, b, 2011; Petropavlovskikh et al. 2015) to determine low ozone episodes. Furthermore, only few studies focused on changes in the UV field during low ozone episodes and the general connection between low ozone episodes and UV extremes (e.g., Anton et al. 2008; Fragkos et al. 2016; Martinez-Lozano et al. 2011; Rieder et al. 2010c).

All abovementioned concepts to define UV and TCO extremes show limitations, and no threshold approach is particularly suited for the joint analysis of ozone and UV extremes. Therefore, a new approach focusing on anomaly changes is presented in this study. In this analytical framework, daily mean values of both UVI and TCO are converted to deviations from climatological daily means (derived based on linearly interpolated monthly means) in terms of (linearly interpolated) standard deviation. This approach avoids (1) the use of a unique threshold throughout the year (thus allows addressing seasonal variations), (2) unphysical "steps" between threshold values at the transition between two consecutive months (in analogy to the method described (for TCO) by Rieder et al. 
(2010a)), and (3) issues due to differences in the evolution of seasonal cycles of TCO and UV as exceedances of individual anomalies are considered. Thus, the presented approach yields daily anomaly values for the ultraviolet radiation index $(\triangle \mathrm{UVI})$ and the total column ozone amount $(\Delta \mathrm{TCO})$ (see Eq. 1):

$\Delta X_{i}=\frac{X_{i}-\overline{X_{M, i}}}{\sigma\left(\overline{X_{M, i}}\right)}$

where the subscript $i$ refers to a daily observation of the variable $X, X$ refers to TCO or UVI, $\overline{X_{M, i}}$ refers to the linearly interpolated monthly mean of $X$, and $\sigma\left(\overline{\left.X_{M, i}\right)}\right.$ refers to the linearly interpolated monthly standard deviation of $X$, respectively. This approach provides a joint framework for the analysis of extremes without further consideration of seasonal variations.

In the following, we refer to days with TCO anomaly smaller than minus one (two) as low (extreme low) ozone days and days with UVI anomaly greater than one (two) as high (extreme high) UV days. Figure 2 shows the number of low ozone and high UV days per year for each site in 1999-2015. We note that the apparent increase in the number of high UV days at some stations towards the end of the time series can be associated with a distinct increase in data coverage at these sites. We note that no such increase is found when the data is analyzed in relative terms.

\subsection{Definition of low ozone episodes and extreme low ozone episodes based on a merged multi-site dataset}

As individual observational records of TCO are incomplete (i.e., missing values due to meteorological conditions, instrument failures, instrument maintenance, and site operation schedules), we pool information contained in the individual records for the analysis of extreme ozone episodes. Such pooling is justified as statistical analysis shows good agreement among individual records: (1) correlation coefficients for joint observations among TCO sites range between 0.87 (0.94) and 0.98 (0.97) for daily (monthly) means, (2) monthly mean differences range between 14.1 and $-1.6 \mathrm{DU}$, and (3) monthly mean absolute differences range between 4.0 and 14.9 DU. As we are particularly interested in low ozone events, we retain only the daily minimum TCO anomaly across observing sites in a merged TCO dataset. The number of low ozone days per year for the merged time series is shown in Fig. 2a. Hereinafter, low (extreme low) ozone episodes (LOEs/eLOEs) are defined as periods of more than two consecutive days with an ozone anomaly smaller than minus one (two) in the merged TCO dataset.

\subsection{An empirical method for the exclusion of dubious UV data from observational records based on TCO and $\mathrm{SD}_{\text {rel }}$}

To identify days with dubious UV observations, a multiple linear regression model for $\triangle \mathrm{UVI}$ using $\triangle \mathrm{TCO}$ and $\mathrm{SD}_{\text {rel }}$ as explanatory variables was developed:

$\Delta U V I_{M o d} \sim I+\beta_{T C O} \cdot \Delta T C O+\beta_{S D} \cdot S D_{r e l}$

where $\Delta \mathrm{UVI}_{\mathrm{Mod}}$ is the UVI anomaly as predicted for given $\triangle \mathrm{TCO}$ and $\mathrm{SD}_{\mathrm{rel}}$ with the regression coefficients $\beta_{T C O}, \beta_{S D}$, and intercept $I$. Any data point with $\Delta$ UVI smaller than a threshold $T$ (which is the multiple regression modelpredicted $\Delta \mathrm{UVI}_{\mathrm{Mod}}$ minus an empirically determined constant of 1.5) is excluded from further analysis. For convenient reference, a representative example for the three-dimensional
Table 2 Overview of site abbreviation, site altitude, and data coverage for individual Austrian UV-B monitoring sites and measurements of sunshine duration co-located (or at nearby meteorological sites)

\begin{tabular}{|c|c|c|c|c|c|}
\hline UV station & $\begin{array}{l}\text { Site } \\
\text { abbreviation }\end{array}$ & $\begin{array}{l}\text { Altitude } \\
(\mathrm{m})\end{array}$ & $\begin{array}{l}\text { UV data coverage } \\
(\%)\end{array}$ & SD station & $\begin{array}{l}\text { SD data coverage } \\
(\%)\end{array}$ \\
\hline Sonnblick & Son & 3106 & 60.1 & Sonnblick & 92.9 \\
\hline Hafelekar $^{\mathrm{a}}$ & Hfk & 2275 & 88.1 & Patscherkofel & 92.3 \\
\hline Gerlitzen $^{\mathrm{a}}$ & Ger & 1526 & 91.2 & Kanzelhöhe & 99.4 \\
\hline Mariapfarr & $\mathrm{Mpf}$ & 1153 & 72.8 & Mariapfarr & 93.7 \\
\hline Innsbruck & Ibk & 577 & 73.7 & Innsbruck & 99.6 \\
\hline Klagenfurt & Kla & 448 & 66.9 & Klagenfurt & 97.0 \\
\hline Dornbirn & Dor & 410 & 56.2 & Dornbirn & 95.4 \\
\hline Graz & Gra & 348 & 72.2 & Graz & 97.2 \\
\hline $\operatorname{Linz}$ & Lin & 335 & 85.1 & $\operatorname{Linz}$ & 96.5 \\
\hline Bad Vöslau & Voe & 286 & 85.6 & Baden & 83.6 \\
\hline Gross-Enzersdorf $^{a}$ & Ged & 156 & 72.1 & Gross-Enzersdorf & 96.9 \\
\hline Vienna & Vie & 153 & 56.1 & Vienna & 94.1 \\
\hline
\end{tabular}

Data coverage is calculated over the period 1999 to 2015

${ }^{\text {a }}$ Shorter records spanning from 2004 to 2015 
Fig. 2 a Number of low ozone days, i.e., days with a strongly negative total column ozone (TCO) anomaly $(\triangle \mathrm{TCO}<-1)$, per year and TCO monitoring site and for the merged TCO dataset. b Number of high UV days, i.e., days with a strongly positive UVI anomaly $(\Delta U V I>1)$ per year and UV-B monitoring site a

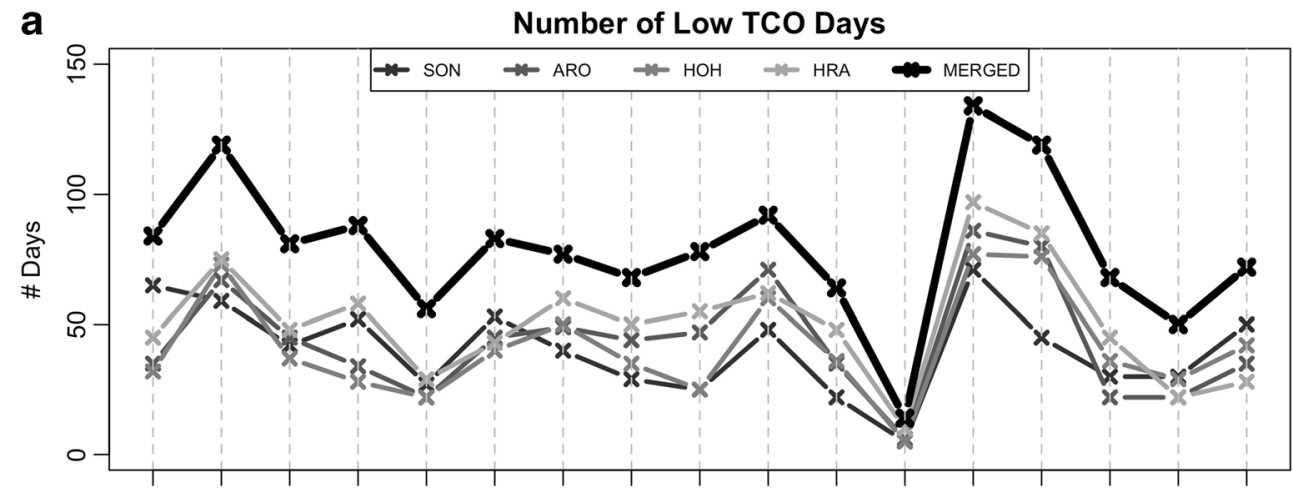

b

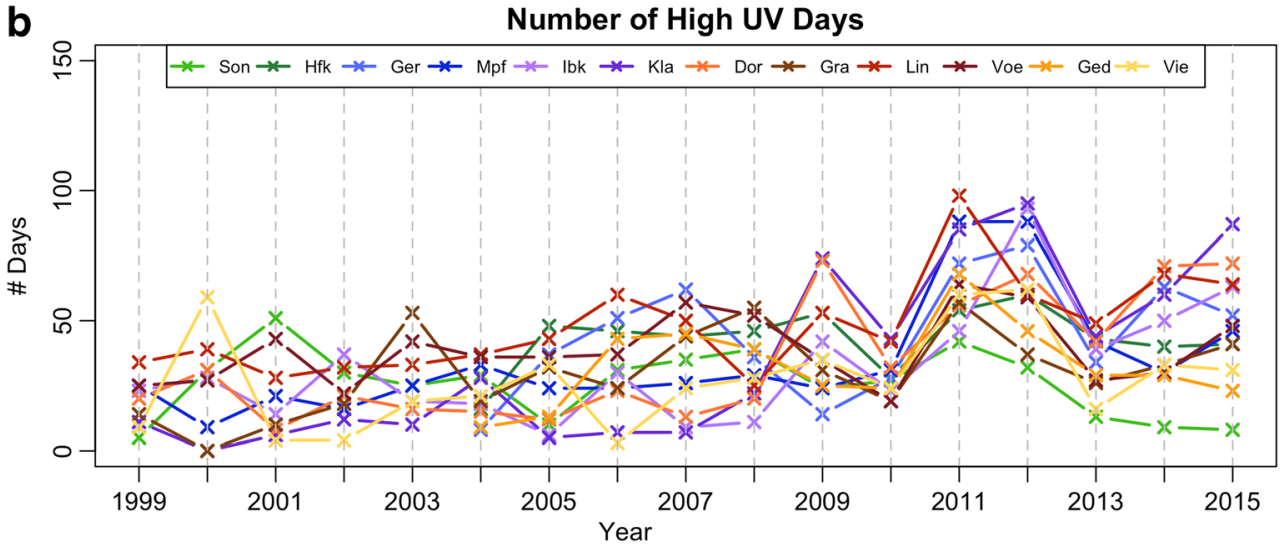

scatterplot between $\triangle \mathrm{UVI}, \triangle \mathrm{TCO}$, and $\mathrm{SD}_{\text {rel }}$ with the cutoff plane for dubious data is shown in Fig. 3, along with the daily course of UVI and $\mathrm{SD}_{\text {rel }}$ data for a selected day classified as "dubious." This method can further be implemented as plausibility check within the operational routine of the Austrian UV-B monitoring network to aid data quality management. a

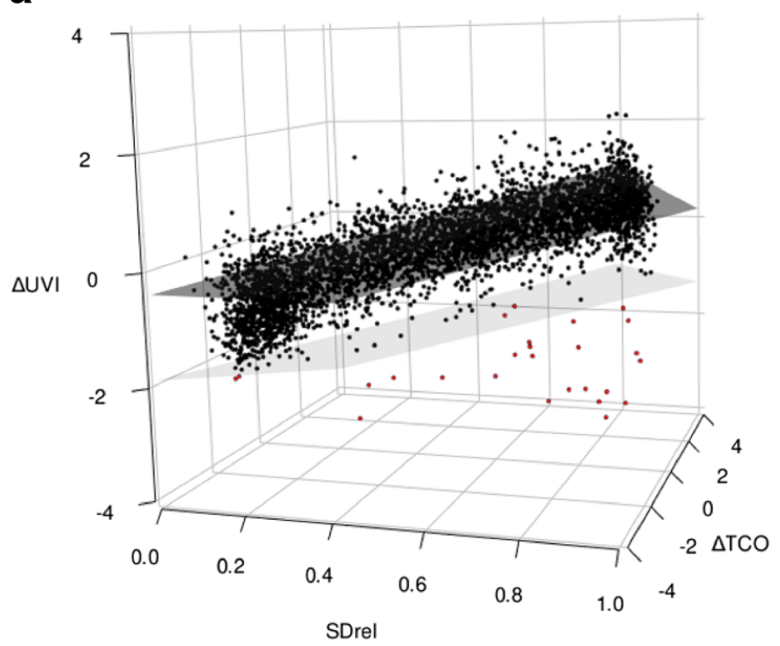

Fig. 3 a The $3 \mathrm{D}$ scatterplot for UVI anomaly $(\Delta \mathrm{UVI})$ and $\mathrm{SD}_{\text {rel }}$ from monitoring site Graz and the regional minimum total ozone anomaly ( $\triangle \mathrm{TCO}$ ). The dark gray vertical plane indicates the fit of the multiple linear regression model illustrated in Eq. (2), while the light gray plane represents the cutoff plane for dubious days $\left(\Delta \mathrm{UVI}_{\mathrm{Mod}}-1.5\right)$. The red points indicate dubious days, and the black points indicate valid measurements. b Diurnal variation of UVI and $\mathrm{SD}_{\text {rel }}$ at station Graz on February 26, 2002 as an exemplary day with dubious UV-B b

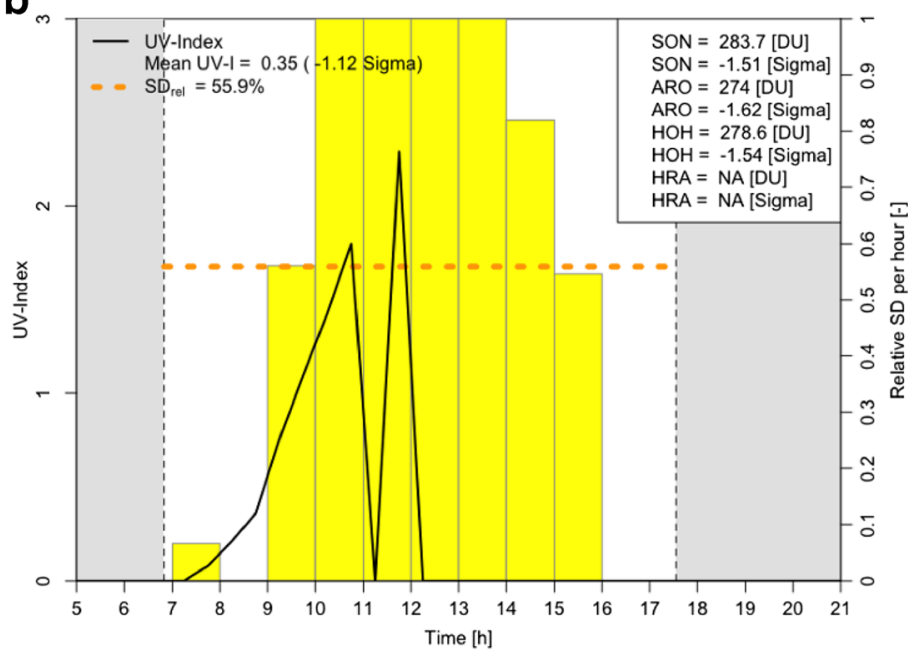

measurements. The gray areas indicate the time periods before (after) sunrise (sunset), the yellow vertical bars give the relative hourly sunshine duration, the black solid line gives the half hourly mean UVI, and the orange dashed line gives the daily mean relative sunshine duration. Information on daily mean UVI and $\mathrm{SD}_{\text {rel }}$ is provided in the top left corner of the panel, while information on TCO (in DU and anomalies) for the four TCO monitoring sites is provided in the top right 
Table 3 Start date, end date, and duration of selected low ozone episodes (LOEs)

\begin{tabular}{|c|c|c|}
\hline Start date & End date & Duration (days) \\
\hline 26.11.1999 & 03.12 .1999 & 8 \\
\hline 31.01 .2000 & 06.02 .2000 & 7 \\
\hline 05.03 .2000 & 12.03 .2000 & 8 \\
\hline 13.04 .2000 & 23.04 .2000 & 12 \\
\hline 01.06 .2000 & 16.06 .2000 & 16 \\
\hline 11.10 .2001 & 21.10 .2001 & 11 \\
\hline 10.07 .2002 & 16.07 .2002 & 7 \\
\hline 18.03 .2003 & 24.03 .2003 & 7 \\
\hline 04.01 .2005 & 11.01 .2005 & 8 \\
\hline 15.03 .2005 & 25.03 .2005 & 11 \\
\hline 27.10 .2005 & 04.11 .2005 & 9 \\
\hline 25.10 .2006 & 31.10 .2006 & 7 \\
\hline 25.12 .2006 & 01.01 .2007 & 8 \\
\hline 14.07 .2007 & 21.07.2007 & 8 \\
\hline 18.02 .2008 & 28.02 .2008 & 11 \\
\hline 24.05 .2008 & 30.05 .2008 & 7 \\
\hline 07.09 .2008 & 13.09 .2008 & 7 \\
\hline 28.03.2011 & 03.04.2011 & 7 \\
\hline 06.04 .2011 & 12.04 .2011 & 7 \\
\hline 16.04 .2011 & 23.042011 & 8 \\
\hline 27.04 .2011 & 30.04 .2011 & 4 \\
\hline 17.08.2011 & 30.08 .2011 & 14 \\
\hline 08.09.2011 & 17.09 .2011 & 10 \\
\hline 28.10 .2011 & 06.11 .2011 & 10 \\
\hline 23.12 .2011 & 29.12 .2011 & 7 \\
\hline 26.04 .2012 & 02.05 .2012 & 7 \\
\hline 15.06 .2012 & 21.06 .2012 & 7 \\
\hline 27.06 .2012 & 03.07 .2012 & 7 \\
\hline 05.07 .2012 & 11.07 .2012 & 7 \\
\hline 17.08 .2012 & 25.08 .2012 & 9 \\
\hline 17.10 .2012 & 24.10 .2012 & 8 \\
\hline 19.12.2015 & 29.12 .2015 & 11 \\
\hline
\end{tabular}

Note that each listed episode lasts longer than 6 days

\section{Results}

In the following, the climatology of low ozone episodes and extreme low ozone episodes in Austria between 1999 and 2015 (Sect. 4.1), the relationship between ozone and UV extremes (Sect. 4.2), and a so-called anomaly amplification factor (AAF) relating changes in TOC anomalies to changes in UV anomalies under clear-sky and partly cloudy conditions (Sect. 4.3) are presented. As it is well understood that UV levels are highest under low TCO and clear-sky or partly cloudy conditions (e.g., Calbo et al. 2005; Rieder et al. 2010c), particular emphasis is given on the analysis of the
Table 4 Start date, end date, and duration of extreme low ozone episodes (eLOEs)

\begin{tabular}{|c|c|c|}
\hline Start date & End date & Duration (days) \\
\hline 05.01.1999 & 06.01.1999 & 2 \\
\hline 01.12.1999 & 02.12 .1999 & 2 \\
\hline 25.09 .2000 & 27.09 .2000 & 3 \\
\hline 29.11.2000 & 30.11 .2000 & 2 \\
\hline 11.02 .2002 & 12.02 .2002 & 2 \\
\hline 01.05 .2002 & 02.05 .2002 & 2 \\
\hline 19.03.2005 & 22.03 .2005 & 4 \\
\hline 02.05 .2005 & 03.05 .2005 & 2 \\
\hline 27.06 .2005 & 28.06 .2005 & 2 \\
\hline 19.01 .2006 & 20.01 .2006 & 2 \\
\hline 27.10 .2006 & 28.10 .2006 & 2 \\
\hline 30.10 .2006 & 31.10 .2006 & 2 \\
\hline 16.07 .2007 & 19.07.2007 & 4 \\
\hline 19.02 .2008 & 22.02 .2008 & 4 \\
\hline 26.05 .2008 & 28.05 .2008 & 3 \\
\hline 12.09 .2008 & 13.09 .2008 & 2 \\
\hline 09.04.2011 & 10.04 .2011 & 2 \\
\hline 16.04 .2011 & 17.04 .2011 & 2 \\
\hline 21.08 .2011 & 22.08 .2011 & 2 \\
\hline 24.08 .2011 & 25.08 .2011 & 2 \\
\hline 26.12 .2011 & 28.12 .2011 & 3 \\
\hline 11.05 .2012 & 12.05 .2012 & 2 \\
\hline 30.06 .2012 & 01.07 .2012 & 2 \\
\hline 25.12 .2012 & 26.12.2012 & 2 \\
\hline 23.09 .2013 & 24.09 .2013 & 2 \\
\hline 16.03 .2014 & 18.03 .2014 & 3 \\
\hline 03.05 .2015 & 05.05 .2015 & 3 \\
\hline
\end{tabular}

Note that each listed episode lasts at least 2 days

relationship between TCO and UVI anomalies on days with $\mathrm{SD}_{\text {rel }} \geq 80 \%$.

\subsection{Identification of low and extreme low ozone episodes}

First, we turn the focus to the climatology of low and extreme low ozone episodes over the GAR. Over the period 1999 to 2015, a total of 300 LOEs and 28 eLOEs have been identified (see Tables 3 and 4). The longest LOE occurred between June 1 and 16, 2000. During this LOE, the highest daily maximum UVI (11.5) within the observational period was observed at monitoring site Sonnblick (June 10, 2000). Overall, 97 of the highest 100 UVI maxima have been observed at this monitoring site, which is not surprising given the high-altitude location of the station $(3106 \mathrm{~m}$ asl $)$ and the known altitude dependence of UV radiation (e.g., Blumthaler et al. 1997; Schmucki and Philipona 2002). The three longest continuous eLOEs persisted 4 days (see Table 4) and were embedded in LOEs lasting 8 days or more. Additionally, in 
Fig. 4 Temporal evolution of the regional minimum total column ozone anomaly $\left(\Delta \mathrm{TCO}_{\min }\right.$, bold black line), ultraviolet radiation index anomaly $(\Delta \mathrm{UVI})$ at individual UV-B monitoring sites (colored lines), and daily mean relative sunshine duration (yellow bars) averaged across available monitoring sites during a the eLOEs/LOE in April 2011, b the eLOE/LOE in March 2005, and c the eLOE/LOE in August 2011. The red shaded areas indicate the eLOEs, time periods between the gray vertical bars indicate the LOEs, and the gray shaded areas indicate the non-extreme ozone episodes

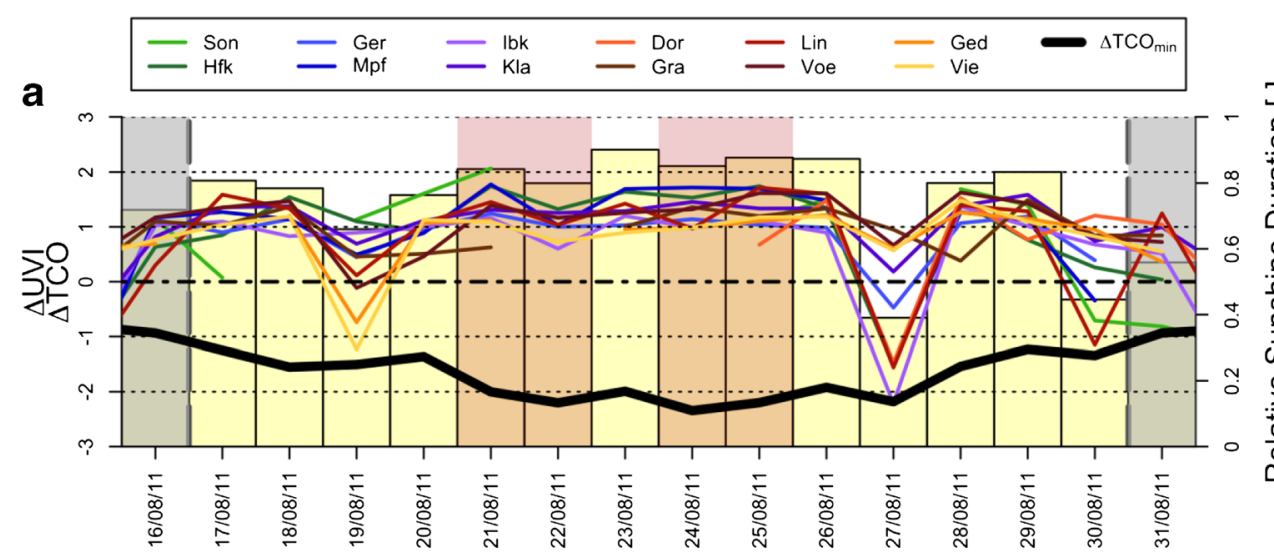

b
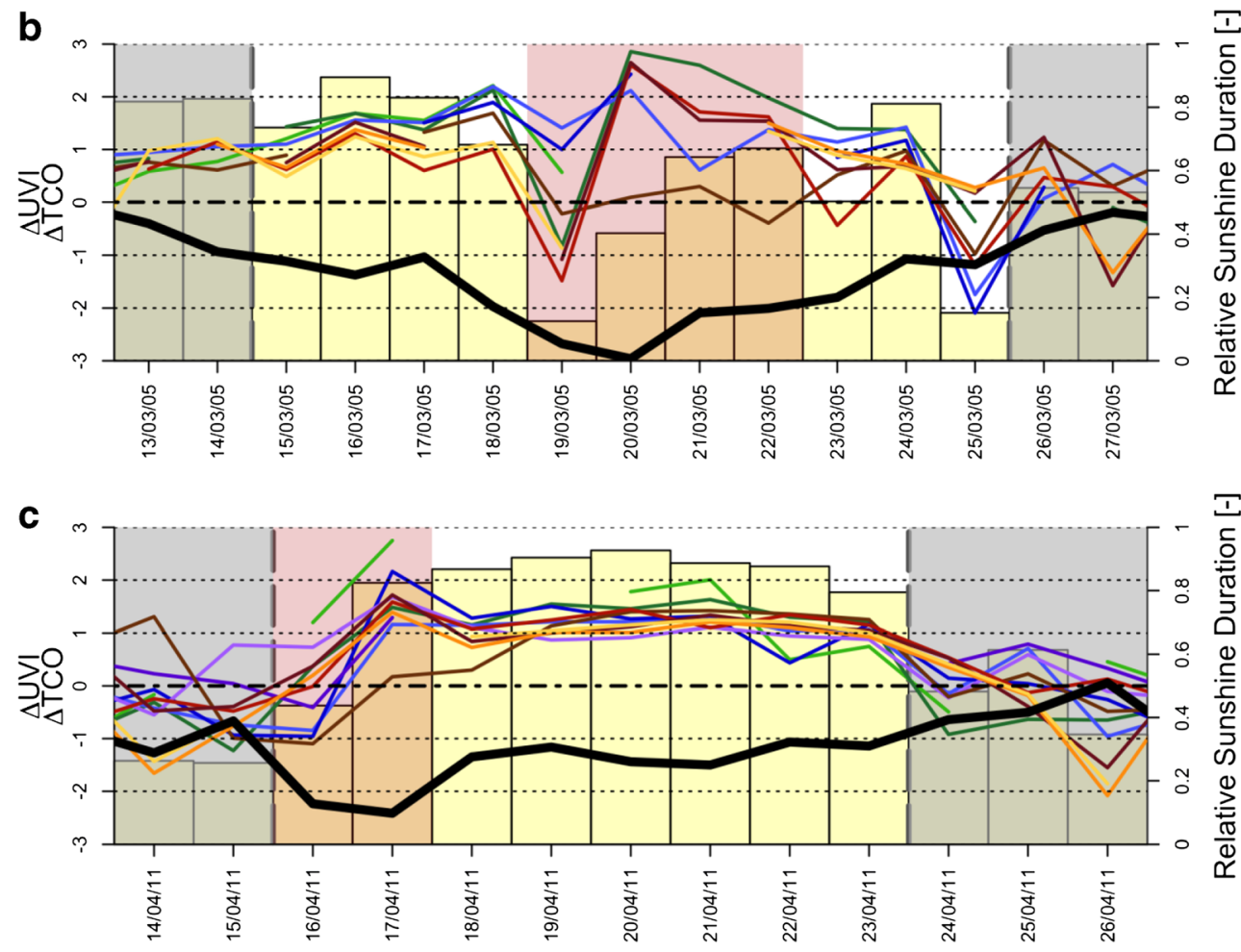

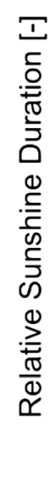

August 2011, four extreme low ozone days forming two eLOEs (i.e., one low ozone day separates the eLOEs) were identified, which were embedded in a 10-day LOE (see Fig. 4a). Given the overall large number of LOEs (300) and eLOEs (28), we focus in the following on selected episodes in greater detail.

In the recent literature, particular emphasis has been given on the identification of low ozone episodes at northern midlatitudes following the advection of ozone poor air masses out of the Arctic polar region. Such advection of ozone poor air occurred more often in recent years as a result of several particularly cold winters, e.g., 2000, 2005, and 2011, with large polar stratospheric cloud (PSC) formation (e.g., Manney et al. 2011). PSC surfaces act as catalysts for the conversion of chlorine reservoir species to active chlorine radicals, which-once sunlight returns in Arctic spring-facilitate significant ozone depletion (e.g., Peter 1997; Solomon 1999). Following the breakup of the Arctic polar vortex in spring, the advection of ozone poor air masses to midlatitudes can occur, which then in turn can lead there to a significant increase in UV radiation as observed most recently in 2011 (e.g., Bernhard et al. 2013).

The outward propagation of ozone poor air masses from the Arctic in spring 2000 triggered one of the longest LOEs on record, lasting from April 13 to 24, 2000. Unfortunately, the influence of this LOE on UV radiation in Austria has been hard to assess, as only a limited number of UV observations is available during this period. In contrast during the LOE in March 2005, complete records of UV observations are available at almost all monitoring sites. The initial phase of this LOE was characterized by 
strongly negative TCO anomalies resulting in a 4-day eLOE from March 19 to 22, 2005 (see Fig. 4b). Despite pronounced TCO anomalies, UVI anomalies have been low to moderate throughout most of the LOE as predominantly cloudy conditions prevailed. In the Arctic spring of 2011, ozone loss rates have been, for the first time, comparable to average Antarctic conditions (e.g., Manney et al. 2011). Propagation of ozone poor Arctic air masses affected large parts of Europe in March and April 2011. In the GAR, ozone poor Arctic air encountered ozone-rich ambient air; thus, local TCO anomalies have been moderated. Nevertheless, three extended LOEs totaling 26 low ozone (and 4 extreme low ozone) days have been identified: March 28 to April 3, April 6 to 12, April 16 to 23, and April 27 to 30. Particularly, during the LOE from April 17 to 23, UVI anomalies have been positive nationwide due to fair weather conditions (see Fig. 4c).

\subsection{Impact of low ozone episodes on ultraviolet radiation}

To analyze the influence of low ozone episodes on UV radiation in Austria, a joint analysis of TCO and UVI anomalies under consideration of $\mathrm{SD}_{\text {rel }}$ has been performed. The following results are based on the TCO record from Sonnblick only, since the station has the smallest spatial distance to most Austrian UV-B monitoring sites.

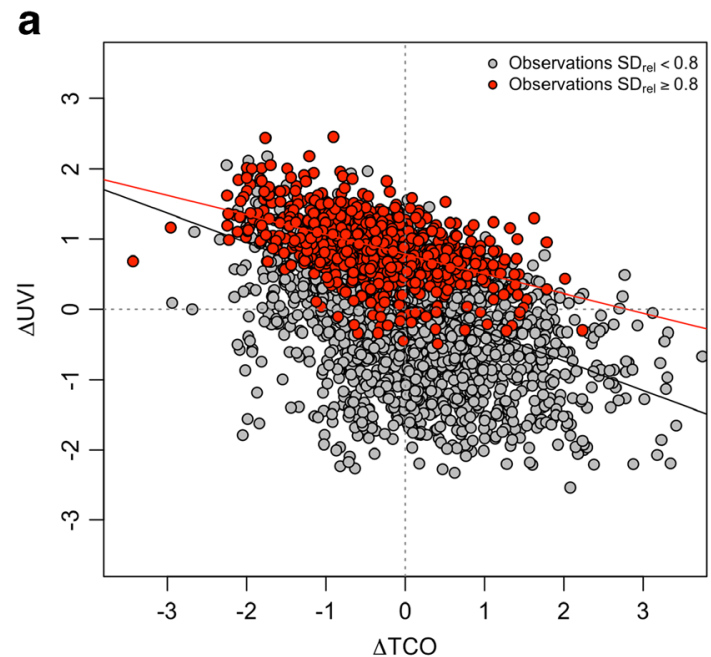

Fig. 5 a Scatterplot of daily anomalies of TCO (observed at site Sonnblick) and UVI (observed at site Graz). The red dots indicate the days with $\mathrm{SD}_{\text {rel }} \geq 80 \%$, and the gray dots indicate the days with $\mathrm{SD}_{\text {rel }}$ between 0 and $80 \%$. The solid lines are the regression lines between TCO and UVI anomalies for all data (black) and days with $\mathrm{SD}_{\text {rel }} \geq 80 \%$ (red). b Scatterplot of daily UVI anomalies against daily relative sunshine duration at station Graz. The red dots indicate the days with $\Delta \mathrm{TCO}<-1$, the blue dots indicate the days with $\Delta \mathrm{TCO}>1$, and the
The results show a significant negative correlation of $\triangle \mathrm{TCO}$ and $\Delta \mathrm{UVI}$. A particularly strong relationship is found for days with clear-sky and partly cloudy conditions $\left(\mathrm{SD}_{\mathrm{rel}} \geq 80 \%\right)$. This is illustrated exemplarily in Fig. 5 for station pair Graz $\left(\Delta \mathrm{UVI}, \mathrm{SD}_{\mathrm{rel}}\right)$ and Sonnblick $(\triangle \mathrm{TCO})$. Figure $5 \mathrm{a}$ shows a scatterplot for $\triangle \mathrm{TCO}$ and $\triangle \mathrm{UVI}$, and Fig. $5 \mathrm{~b}$ shows a scatterplot for $\mathrm{SD}_{\text {rel }}$ and $\triangle \mathrm{UVI}$, respectively. Expanding the joint analysis of $\triangle \mathrm{UVI}, \triangle \mathrm{TCO}$, and $\mathrm{SD}_{\text {rel }}$ across all UV-B monitoring sites (see Table 5) shows that during 1999-2015, more than $65 \%$ of observations with low TCO anomaly $(\Delta \mathrm{TCO}<-1)$ led to positive UVI anomalies $(\Delta \mathrm{UVI}>0)$ independent of sunshine duration and site. Furthermore, for days with $\mathrm{SD}_{\text {rel }}>40 \%$ and strongly negative $\mathrm{TCO}$ anomaly $(\triangle \mathrm{TCO}<-1)$, more frequently positive than negative $\triangle \mathrm{UVI}$ is found. On the other hand, on days with strongly positive TCO anomaly $(\Delta \mathrm{TCO}>1)$, more positive than negative UVI anomalies have been observed only on days with at least $80 \%$ relative sunshine duration at the majority of sites.

Considering only days with strongly positive UVI anomaly ( $\Delta$ UVI $>1$ ), we find across all sites: (1) about $50 \%$ correspond to strongly negative or extremely negative ozone anomalies, (2) about $90 \%$ correspond to negative $\triangle \mathrm{TCO}$, and (3) the remaining $10 \%$ occur during fair weather conditions $\left(\mathrm{SD}_{\text {rel }} \geq 80 \%\right)$ explaining a strongly positive $\triangle \mathrm{UVI}$ despite positive TCO anomalies (see Fig. 6).

b

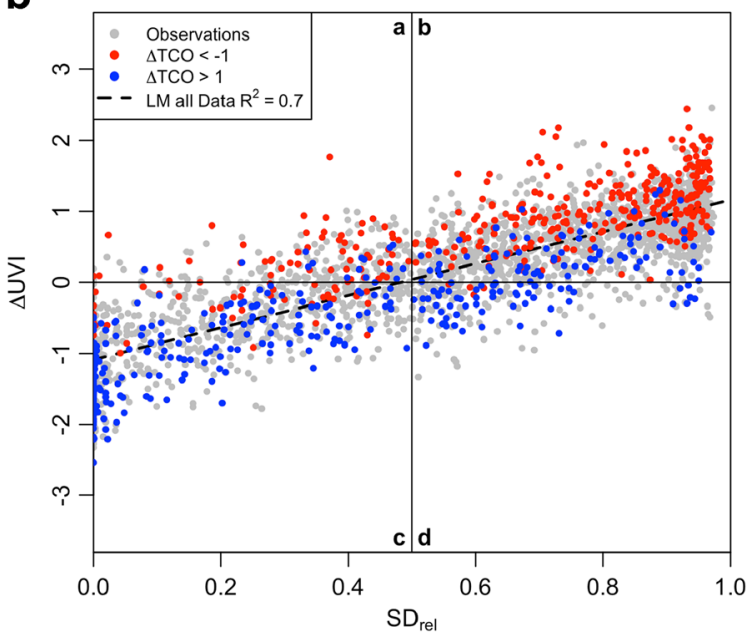

gray dots indicate all other days (note that TCO data is from site Sonnblick). The dashed black line gives the regression line between $\triangle \mathrm{UVI}$ and $\mathrm{SD}_{\text {rel }}$ for all available data. Explained variance $\left(R^{2}\right)$ of the regression model is given in the upper left corner of the graph. The figure is subdivided in four regions of interest, divided through a crosshair centered at $\Delta \mathrm{UVI}=0$ and $\mathrm{SD}_{\text {rel }}=0.5$, indicated with $a$ (positive $\Delta \mathrm{UVI}$ and $\mathrm{SD}_{\text {rel }}<0.5$ ), $b$ (positive $\Delta \mathrm{UVI}$ and $\mathrm{SD}_{\text {rel }} \geq 0.5$ ), $c$ (negative $\Delta \mathrm{UVI}$ and $\mathrm{SD}_{\text {rel }}<0.5$ ), and $d$ (negative $\Delta \mathrm{UVI}$ and $\mathrm{SD}_{\text {rel }} \geq 0.5$ ) 
Table 5 Percentage of days with strongly negative $\left(\Delta \mathrm{TCO}^{(-)}\right.$, i.e., $\left.\Delta \mathrm{TCO}<-1\right)$ and strongly positive $\left(\Delta \mathrm{TCO}^{(+)}\right.$, i.e., $\left.\Delta \mathrm{TCO}>1\right) \mathrm{TCO}$ anomaly for days with (a) positive $\Delta \mathrm{UVI}$ and $\mathrm{SD}_{\text {rel }}<50 \%$, (b) positive $\Delta \mathrm{UVI}$ and $\mathrm{SD}_{\text {rel }} \geq 50 \%$, (c) negative $\Delta \mathrm{UVI}$ and $\mathrm{SD}_{\text {rel }}<50 \%$, and (d) negative $\Delta \mathrm{UVI}$ and $\mathrm{SD}_{\text {rel }} \geq 50 \%$

\begin{tabular}{|c|c|c|c|c|c|c|c|c|}
\hline \multirow[t]{2}{*}{ Site } & \multicolumn{2}{|l|}{$\mathrm{a}$} & \multicolumn{2}{|l|}{$\mathrm{b}$} & \multicolumn{2}{|l|}{$\mathrm{c}$} & \multicolumn{2}{|l|}{$\mathrm{d}$} \\
\hline & $\Delta \mathrm{TCO}^{(-)}$ & $\Delta \mathrm{TCO}^{(+)}$ & $\Delta \mathrm{TCO}^{(-)}$ & $\Delta \mathrm{TCO}^{(+)}$ & $\Delta \mathrm{TCO}^{(-)}$ & $\Delta \mathrm{TCO}^{(+)}$ & $\Delta \mathrm{TCO}^{(-)}$ & $\Delta \mathrm{TCO}^{(+)}$ \\
\hline Son & $2.5(18.5)$ & 1.7 (11.4) & $7.0(52.1)$ & $1.5(10.1)$ & $3.9(28.8)$ & $9.8(66.2)$ & $0.1(0.5)$ & $1.8(12.3)$ \\
\hline Hfk & $1.7(12.3)$ & $0.7(4.4)$ & $8.9(65.7)$ & $2.2(14.3)$ & $2.6(19.2)$ & $11.0(70.1)$ & $0.4(2.8)$ & $1.7(11.2)$ \\
\hline Ger & $1.5(10.7)$ & $0.3(1.9)$ & $10.6(77.0)$ & $2.1(13.7)$ & $1.7(12.0)$ & $11.4(72.6)$ & $0.0(0.3)$ & $1.8(11.8)$ \\
\hline Mpf & $3.0(20.7)$ & $0.7(4.6)$ & $8.0(56.0)$ & $1.7(11.5)$ & $3.2(22.3)$ & $11.1(74.4)$ & $0.1(1.0)$ & $1.4(9.5)$ \\
\hline Ibk & $2.4(17.1)$ & $0.6(3.7)$ & $8.5(59.9)$ & $2.7(18.5)$ & $3.1(22.2)$ & $10.1(68.4)$ & $0.1(0.8)$ & $1.4(9.4)$ \\
\hline Kla & $2.7(18.0)$ & $1.0(7.0)$ & $8.6(58.2)$ & $2.6(17.9)$ & $3.4(22.9)$ & $9.6(67.1)$ & $0.1(0.9)$ & $1.2(8.1)$ \\
\hline Dor & $3.5(23.4)$ & $1.7(13.1)$ & $6.2(41.7)$ & 2.9 (21.9) & $5.1(34.6)$ & $8.4(63.1)$ & $0.0(0.3)$ & $0.3(2.0)$ \\
\hline Gra & $1.8(12.3)$ & $0.4(3.0)$ & $10.0(67.0)$ & $2.5(17.8)$ & $2.9(19.5)$ & 8.9 (64.6) & $0.2(1.2)$ & $2.0(14.6)$ \\
\hline Lin & $2.5(17.4)$ & $1.3(8.7)$ & $7.3(51.3)$ & $2.1(14.5)$ & $4.5(31.3)$ & $10.7(72.9)$ & $0.0(0.0)$ & $0.6(3.8)$ \\
\hline Voe & $2.4(17.1)$ & $1.2(8.1)$ & $7.1(50.8)$ & $2.8(18.7)$ & $4.4(31.4)$ & $10.6(69.4)$ & $0.1(0.6)$ & $0.6(3.8)$ \\
\hline Ged & $2.2(17.3)$ & $0.9(5.8)$ & $6.9(54.4)$ & $2.9(17.8)$ & $3.6(28.3)$ & $11.3(69.6)$ & $0.0(0.0)$ & $1.1(6.8)$ \\
\hline Wie & $2.1(13.9)$ & $1.4(9.3)$ & $8.3(55.4)$ & $2.3(14.7)$ & $4.5(29.7)$ & $11.1(72.0)$ & $0.2(1.0)$ & $0.6(4.1)$ \\
\hline
\end{tabular}

The first values in each column represent the percentage of days with respect to all available observations at this site, while values in brackets give the percentage with respect to all strongly negative/strongly positive TCO observations

\subsection{An AAF relating changes in TCO and UVI}

To assess the general relationship between TCO and UVI anomalies, we introduce an AAF in analogy to the radiation amplification factor frequently used in previous work (e.g., McKenzie et al. 1991). This AAF quantifies the expected change of the $\Delta \mathrm{UVI}$ for a given change in $\triangle \mathrm{TCO}$ (i.e., the slope of the regression lines in Fig. 5a), independent of seasonal and inter-annual variations. To avoid masking effects of cloudiness (represented here by $\mathrm{SD}_{\text {rel }}$ ), only observations with clear-sky and partly cloudy conditions $\left(\mathrm{SD}_{\text {rel }} \geq 80 \%\right)$ have been taken into account for calculation of the AAF. The mean AAF across all considered UV-B monitoring sites

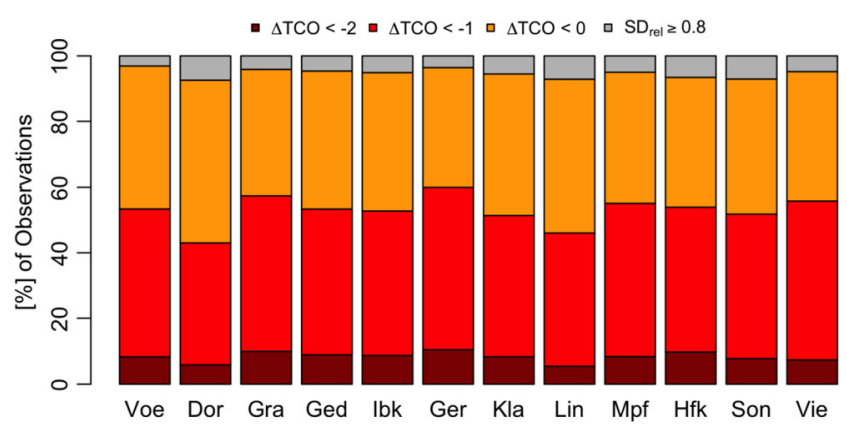

Fig. 6 Fraction of observation days (in \%) with strongly positive UVI anomaly $(\Delta \mathrm{UVI}>1)$ categorized into days with extremely negative $(\Delta \mathrm{TCO}<-2$, dark red $)$, strongly negative $(-2 \leq \Delta \mathrm{TCO}<-1$, red $)$, negative $(-1 \leq \Delta \mathrm{TCO}<0$, orange $)$, and positive TCO anomaly combined with high relative sunshine duration $(\triangle \mathrm{TCO}>0$ and $\mathrm{SD}_{\text {rel }} \geq 80 \%$, gray) over the whole observational period was found to be 0.32 with a mean absolute deviation of 0.05 .

\section{Conclusions and discussion}

Within this study, we address the influence of low TCO on UV-B radiation in Austria. To this aim, we analyze data from four TCO monitoring sites in the Greater Alpine Region (Arosa, Switzerland; Hohenpeissenberg, Germany; Hradec Kralove, Czech Republic; Sonnblick, Austria) and 12 UV-B monitoring sites operated within the scope of the Austrian UV-B monitoring network from 1999 to 2015. Given the importance of ambient weather conditions (i.e., cloudiness) for erythemal UV-B doses, we include information on relative sunshine duration $\left(\mathrm{SD}_{\text {rel }}\right)$ observed at or nearby the UV monitoring sites.

As none of the definitions for low ozone episodes presented in the scientific literature is particularly suited for the joint analysis of ozone and UV extremes, we present a novel approach focusing on anomaly changes (see Sect. 3). Our approach avoids (1) the use of a unique threshold throughout the year (thus allows addressing seasonal variations), (2) unphysical steps between threshold values at the transition between two consecutive months, and (3) issues due to differences in the seasonal cycles of TCO and UV as exceedances of individual anomalies are considered. Therefore, it can be regarded as improved time-varying threshold approach, allowing not only the identification of ozone extremes but also their specific impact on erythemal UV-B radiation. 
As individual TCO records are incomplete, we pool information and consider the daily minimum TCO anomaly across sites (Sect. 3.2). Furthermore, we use this daily minimum TCO anomaly to define low (extreme low) ozone episodes (LOE/eLOE) as periods of more than two consecutive days with an ozone anomaly smaller than one (two) standard deviation(s) (Sect. 3.2). Over the period 1999 to 2015, a total of 28 eLOEs and 300 LOEs have been identified in the merged TCO record (Sect. 4.1). Several low ozone episodes occurred following the advection of ozone poor air masses out of the Arctic polar region. Such events occurred more frequent in recent years as the Arctic experienced several particularly cold winters, e.g., 2000, 2005, and 2011, with large polar stratospheric cloud formation (e.g., Manney et al. 2011).

The joint analysis of the TOC and UVI anomalies $(\triangle \mathrm{TCO}$ and $\Delta U V I$, respectively), under consideration of the relative sunshine duration, showed a significant negative correlation especially during fair weather conditions (Sect. 4.2). More than $65 \%$ of observations with a strongly negative TCO anomaly $(\triangle \mathrm{TCO}<-1)$ led to a positive UVI anomaly $(\Delta \mathrm{UVI}>0)$. For days with more than $40 \% \mathrm{SD}_{\text {rel }}$ and a strongly negative TCO anomaly, more frequently positive than negative $\Delta U V I$ has been observed at all sites. On the other hand, on days with strongly positive TCO anomaly, more frequently positive than negative UVI anomalies have commonly been observed on days with at least $80 \% \mathrm{SD}_{\text {rel }}$.

Finally, we introduce an AAF, which quantifies the expected change of the $\triangle \mathrm{UVI}$ for a given change in $\triangle \mathrm{TCO}$ (Sect. 4.3). To avoid masking effects of cloudiness, only observations with clear-sky and partly cloudy conditions have been taken into account. The mean AAF across all considered UV sites over the whole observational period was found to be 0.32 with a mean absolute deviation of 0.05 . Since the AAF quantifies the amplification of the daily mean UVI anomaly, it cannot be directly related to the radiation amplification factor (RAF), which quantifies the expected change in instantaneous $\mathrm{UV}$ irradiance for a given change in TCO. However, the AAF can provide useful information for forecasting UVI anomalies under fair weather conditions from total column ozone predictions and/or to evaluate potential changes in UVI extremes from ozone fields derived from transient chemistry-climate model integrations.

Acknowledgements Open access funding provided by University of Graz. The authors thank Stana Simic (University of Natural Resources and Life Sciences, Vienna) for providing the TCO data from site Sonnblick, Herbert Schill (Swiss Federal Office of Meteorology and Climatology MeteoSwiss), for providing the TCO data from site Arosa, and the station operators of the total ozone monitoring sites Hohenpeissenberg and Hradec Kralove for providing the station data via the WOUDC data portal. The authors are grateful to the Zentralanstalt für Meteorologie und Geodynamik (ZAMG), Austria, for providing the sunshine duration data used in this study. M.S. acknowledges partial support through a fellowship of the University of Graz. Installation and operation of the Austrian UV monitoring network is funded by the Austrian Federal Ministry of Agriculture, Forestry, Environment, and Water Management under grant no. BMLFUWUW.1.4.6/0003-V/4/2009. The authors are grateful for the fruitful comments of two anonymous referees, helping to improve the manuscript.

Open Access This article is distributed under the terms of the Creative Commons Attribution 4.0 International License (http:// creativecommons.org/licenses/by/4.0/), which permits unrestricted use, distribution, and reproduction in any medium, provided you give appropriate credit to the original author(s) and the source, provide a link to the Creative Commons license, and indicate if changes were made.

\section{References}

Anton M, Serrano A, Cancillo ML, Garcia JA (2008) Total ozone and solar erythemal irradiance in southwestern Spain: day-to-day variability and extreme episodes. Geophys Res Lett 35:L20804. doi:10. 1029/2008g1035290

Auer I et al (2007) HISTALP - historical instrumental climatological surface time series of the Greater Alpine Region. Int J Climatol 27:17-46. doi:10.1002/joc.1377

Bais AF, Zerefos CS, Meleti C, Ziomas IC, Tourpali K (1993) Spectral measurements of solar UVB radiation and its relations to total ozone, $\mathrm{SO}_{2}$, and clouds. J Geophys Res-Atmos 98:5199-5204. doi:10.1029/92jd02904

Bartlett LM, Webb AR (2000) Changes in ultraviolet radiation in the 1990s: spectral measurements from reading, England. J Geophys Res-Atmos 105:4889-4893. doi:10.1029/1999jd900493

Bernhard $\mathrm{G}$ et al (2013) High levels of ultraviolet radiation observed by ground-based instruments below the 2011 Arctic ozone hole. Atmos Chem Phys 13:10573-10590. doi:10.5194/acp-13-10573-2013

Blumthaler M, Ambach W (1988) Solar UVB-albedo of various surfaces. Photochem Photobiol 48:85-88

Blumthaler M, Ambach W, Ellinger R (1997) Increase in solar UV radiation with altitude. J Photochem Photobiol B 39:130-134. doi:10. 1016/S1011-1344(96)00018-8

Bojkov RD, Balis DS (2001) Characteristics of episodes with extremely low ozone values in the northern middle latitudes 1957-2000. Ann Geophys 19:797-807

Brönnimann S, Hood LL (2003) Frequency of low-ozone events over northwestern Europe in 1952-1963 and 1990-2000. Geophys Res Lett 30. doi:10.1029/2003g1018431 ASC8-1-5

Calbo J, Pages D, Gonzalez JA (2005) Empirical studies of cloud effects on UV radiation: a review. Rev Geophys 43:RG2002. doi:10.1029/ $2004 \mathrm{rg} 000155$

Commission Internationale de l'Eclairage (1999) Standardization of the terms UV-A1, UV-A2 and UV-B, in collection in photobiology and photochemistry. Commission Internationale de l'Eclairage, Vienna

Engel A, Strunk M, Muller M, Haase HP, Poss C, Levin I, Schmidt U (2002) Temporal development of total chlorine in the high-latitude stratosphere based on reference distributions of mean age derived from $\mathrm{CO}_{2}$ and $\mathrm{SF}_{6}$. J Geophys Res-Atmos 107. doi:10.1029/ 2001jd000584 Artn 4136

Eyring V et al (2010) Multi-model assessment of stratospheric ozone return dates and ozone recovery in CCMVal-2 models. Atmos Chem Phys 10:9451-9472. doi:10.5194/acp-10-9451-2010

Farman JC, Gardiner BG, Shanklin JD (1985) Large losses of total ozone in Antarctica reveal seasonal CLOX/NOX interaction. Nature 315: 207-210

Feister U, Cabrol N, Häder D (2015) UV irradiance enhancements by scattering of solar radiation from clouds. Atmosphere 6:1211 
Fitzka M, Hadzimustafic J, Simic S (2014) Total ozone and Umkehr observations at Hoher Sonnblick 1994-2011: climatology and extreme events. J Geophys Res 119:739-752. doi:10.1002/ 2013JD021173

Fragkos K, Bais AF, Fountoulakis I, Balis D, Tourpali K, Meleti C, Zanis P (2016) Extreme total column ozone events and effects on UV solar radiation at Thessaloniki. Greece Theor Appl Climatol 126:505517. doi:10.1007/s00704-015-1562-3

Frossard L et al (2013) On the relationship between total ozone and atmospheric dynamics and chemistry at mid-latitudes - Part 1: statistical models and spatial fingerprints of atmospheric dynamics and chemistry. Atmos Chem Phys 13:147-164. doi:10.5194/acp-13147-2013

Glandorf M, Arola A, Bais A, Seckmeyer G (2005) Possibilities to detect trends in spectral UV irradiance. Theor Appl Climatol 81:33-44. doi:10.1007/s00704-004-0109-9

Hood LL, Soukharev BE, Fromm M, McCormack JP (2001) Origin of extreme ozone minima at middle to high northern latitudes. J Geophys Res-Atmos 106:20925-20940. doi:10.1029/ 2001 jd900093

Iwao K, Hirooka T (2006) Dynamical quantifications of ozone minihole formation in both hemispheres. J Geophys Res-Atmos:111. doi:10. 1029/2005jd006333

James PM (1998) A climatology of ozone mini-holes over the northern hemisphere. Int J Climatol 18:1287-1303

Kazadzis S et al (2007) Nine years of UV aerosol optical depth measurements at Thessaloniki, Greece. Atmos Chem Phys 7:2091-2101

Kerr JB (2002) New methodology for deriving total ozone and other atmospheric variables from Brewer spectrophotometer direct sun spectra. J Geophys Res Atmos 107(D23):ACH 22-1-ACH 22-17

Kerr JB (2003) Understanding the factors that effect surface UV radiation. Proc SPIE 5156:1-14

Kerr JB, McElroy CT, Wardle DI, Olafson RA, Evans WF (1985) The automated Brewer spectrophotometer. In: Halkidiki C, Zerefos S, Ghazi A, Reidel D (eds) Proc. Quadr. Ozone Symp., Norwell, Mass., pp 396-401

Koch G, Wernli H, Schwierz C, Staehelin J, Peter T (2005) A composite study on the structure and formation of ozone miniholes and minihighs over central Europe. Geophys Res Lett 32:L12810. doi: $10.1029 / 2004$ gl022062

Krzyscin JW (2002) Long-term changes in ozone mini-hole event frequency over the northern hemisphere derived from ground-based measurements. Int J Climatol 22:1425-1439. doi:10.1002/joc.812

Mäder JA, Staehelin J, Peter T, Brunner D, Rieder HE, Stahel WA (2010) Evidence for the effectiveness of the Montreal Protocol to protect the ozone layer. Atmos Chem Phys 10:12161-12171. doi:10.5194/ acpd-10-19005-2010

Manney GL et al (2011) Unprecedented Arctic ozone loss in 2011. Nature 478:469-U465. doi:10.1038/nature 10556

Martinez-Lozano JA et al (2011) Ozone mini-holes over Valencia (Spain) and their influence on the UV erythemal radiation. Int J Climatol 31: 1554-1566. doi:10.1002/joc.2173

McKenzie RL, Matthews WA, Johnston PV (1991) The relationship between erythemal UV and ozone, derived from spectral irradiance measurements. Geophys Res Lett 18:2269-2272. doi:10.1029/ $91 \lg 102786$

Montzka SA et al (1996) Decline in the tropospheric abundance of halogen from halocarbons: implications for stratospheric ozone depletion. Science 272:1318-1322. doi:10.1126/science.272.5266.1318

Montzka SA, Butler JH, Elkins JW, Thompson TM, Clarke AD, Lock LT (1999) Present and future trends in the atmospheric burden of ozonedepleting halogens. Nature 398:690-694. doi:10.1038/19499
Newman PA, Lait LR, Schoeberl MR (1988) The morphology and meteorology of southern-hemisphere spring total ozone mini-holes. Geophys Res Lett 15:923-926. doi:10.1029/G1015i008p00923

Peter T (1997) Microphysics and heterogeneous chemistry of polar stratospheric clouds. Annu Rev Phys Chem 48:785-822

Petropavlovskikh I, Evans R, McConville G, Manney GL, Rieder HE (2015) The influence of the North Atlantic Oscillation and El Niño-Southern Oscillation on mean and extreme values of column ozone over the United States. Atmos Chem Phys 15:1585-1598. doi:10.5194/acp-15-1585-2015

Petzoldt K (1999) The role of dynamics in total ozone deviations from their long-term mean over the northern hemisphere. Ann GeophysAtm Hydr 17:231-241. doi:10.1007/s005850050753

Reuder J, Schwander H (1999) Aerosol effects on UV radiation in nonurban regions. J Geophys Res-Atmos 104:4065-4077. doi:10.1029/ $1998 \mathrm{jd} 200072$

Rieder HE et al (2010a) Extreme events in total ozone over Arosa-Part 1: application of extreme value theory. Atmos Chem Phys 10: 10021-10031

Rieder HE et al (2010b) Extreme events in total ozone over Arosa-Part 2: fingerprints of atmospheric dynamics and chemistry and effects on mean values and long-term changes. Atmos Chem Phys 10: 10033-10045

Rieder HE et al (2010c) Relationship between high daily erythemal UVdoses, total ozone, surface albedo and cloudiness: an analysis of 30 years of data from Switzerland and Austria. Atmos Res 98:9 20. doi:10.1016/j.atmosres.2010.03.006

Rieder HE et al (2011) Extreme events in total ozone over the northern mid-latitudes: an analysis based on long-term data sets from five European ground-based stations. Tellus B 63:860-874. doi:10. $1111 / j .1600-0889.2011 .00575 . x$

Rieder HE et al (2013) On the relationship between total ozone and atmospheric dynamics and chemistry at mid-latitudes - Part 2: the effects of the El Nino/Southern Oscillation, volcanic eruptions and contributions of atmospheric dynamics and chemistry to long-term total ozone changes. Atmos Chem Phys 13:165-179. doi:10.5194/ acp-13-165-2013

Ruckstuhl C et al (2008) Aerosol and cloud effects on solar brightening and the recent rapid warming. Geophys Res Lett 35:L12708. doi:10. 1029/2008g1034228

Schmalwieser AW, Schauberger G (2001) A monitoring network for erythemally-effective solar ultraviolet radiation in Austria: determination of the measuring sites and visualisation of the spatial distribution. Theor Appl Climatol 69:221-229. doi:10.1007/ s007040170027

Schmucki DA, Philipona R (2002) Ultraviolet radiation in the Alps: the altitude effect. Opt Eng 41:3090-3095. doi:10.1117/1.1516820

Seckmeyer G, Erb R, Albold A (1996) Transmittance of a cloud is wavelength-dependent in the UV-range. Geophys Res Lett 23: 2753-2755. doi:10.1029/96g102614

Solomon S (1999) Stratospheric ozone depletion: a review of concepts and history. Rev Geophys 37:275-316

Solomon S, Ivy DJ, Kinnison D, Mills MJ, Neely RR, Schmidt A (2016) Emergence of healing in the Antarctic ozone layer. Science 353: 269-274. doi:10.1126/science.aae0061

SPARC-CCMVal (2010) SPARC Report on the Evaluation of ChemistryClimate Models

UNEP (1998) Environmental effects of ozone depletion: 1998 assessment. United Nations Envrionmental Program, Nairobi

WMO (2014) Scientific assessment of ozone depletion: 2014. Global Ozone Research and Montitoring Project, Report No. 55, Geneva

World Health Organization (2002) Global solar UV index - a practical guide. World Health Organization (WHO), Geneva 